\title{
Efficacy of Facebook Fans: Can They Influence Perception of the Brand?
}

\author{
Mike Behan \\ Dahl School of Business, Viterbo University, La Crosse, WI, USA \\ Email: mkbehan@viterbo.edu
}

Received 25 June 2014; revised 28 July 2014; accepted 15 August 2014

Copyright (C) 2014 by author and Scientific Research Publishing Inc.

This work is licensed under the Creative Commons Attribution International License (CC BY). http://creativecommons.org/licenses/by/4.0/

c) (i) Open Access

\begin{abstract}
Using a qualitative single case study methodology, this research studied the effect that a Facebook page has on friends of the brand. The problem under investigation is the lack of understanding effects social media sites like Facebook has on the perception of the brand by the user. The data collected suggests that the use of Facebook by a SME does help maintain and in some cases increase the perception of the brand in the positive. The analysis of the data additionally shows this effect on brand perception is based on the drivers of a) connectivity, b) change of perception, c) internal value, d) goodwill, and e) the decision process. Interview participants indicate the importance Facebook has as a marketing communication tool. The findings from the research suggest that Facebook use by SMEs is an important component of an integrated approach to marketing communications when considering the perception of the brand. This research also raises important questions as to what significance Facebook use by SMEs has over other traditional marketing communication methods when creating, communicating, and delivering a message of value.
\end{abstract}

\section{Keywords}

Marketing Tactics, Brand Perception, Social Media, Facebook, SME, and IMC

\section{Introduction}

Since the new millennium, the function of marketing has not changed, but the tools used to create, communicate, and deliver a message of value have. Of particular interest among marketers is the use of social media portals like Facebook as a new communication tool. However, to date scholarship has not caught up effectively to investigate the varying implications that Facebook has for both marketing theory and practice [1]-[4]. Specifically, little research exists that examines the effect Facebook has on the perception of the brand in small to medium size enterprises (SMEs). If the intention of using capital and human resource to develop and maintain a Facebook site is part of an overall marketing strategy, then a better understanding of this new and developing phe- 
nomenon is paramount. The research problem then is the lack of understanding of the effect that Facebook use has on the perception of a brand.

Over the last five years businesses have quadrupled their allocation of resources to online and integrated marketing communication methodologies, such as Facebook, Twitter, texting, blogging, etc. [5]. This movement away from the more traditional media options (television, radio, magazines, newspapers, etc.) has been a challenge for marketing managers due to its newness in application [6]. Managers of large and small businesses alike are steadily allocating a larger portion of their marketing dollars towards social media portals to a near $50 \%$ increase in budgeted dollars year over year, with few having a strategic purpose or plan [7] [8]. This is in contrast to the tested traditional methods of marketing communication that have known goals and metrics to measure them. Of all the social media portals, Facebook is the most used and adopted by individuals and businesses [9]. In fact, Hardey [1] and Owen and Humphery [10] believe many opportunities exist for scholarship due to both Facebook's widespread use and relative unknown impact on the user from a marketing perspective.

Facebook, created by Mark Zuckerberg and other principals, was launched in February 2004 as a social networking site for college students on the east coast. Facebook quickly became the leading social media site by both individual users and businesses. It is estimated that Facebook had over 900 million unique users worldwide as of May 2012 [11]. Furthermore, 90\% of social networking is done via Facebook and 4\% of all Internet usage is spent viewing news-feeds by Facebook users [11]. In addition, over 70\% of business owners use Facebook to deliver content to their target market [12]. By having users "like" their Facebook page, businesses can constantly communicate with the users by sending updates, newsfeeds, and commenting on others' posts.

In addition, businesses not only deliver content with text and pictures on their Facebook page, but others also have the ability to create content with their own comments [13]. Because Facebook and organizations have only begun to engage in the business and marketing application of it as of 2008, the purpose and effectiveness of the new tool need to be better identified. Piskorski [14] argued that within the marketing and management ranks, a new social media strategy must be developed within the framework of the overall business strategy. The management dilemma of what role social media portals such as Facebook should play in overall marketing strategy is clear, yet little scholarship in that regard has been done to better guide practitioners [15].

Despite the heavy use of social media by organizations, $70 \%$ of small businesses have a Facebook site [16]; little is known about what effect Facebook has on the user of the brand [12]. Following an integrated marketing communications (IMC) strategy, most organizations big and small similarly brand their product or service in the same way regardless of the medium. IMC strategy requires a seamless approach of the message to the end user by having a similar feel to the promotion whether, a TV, radio, billboard ad, and webpage or in this case Facebook page is used [17]. Given the numerous promotional mix variables, marketers now have the ability to engage the customer in a variety of ways. Understanding how and why social media sites such as Facebook are used within the promotional mix is essential in driving marketing return on investment.

Ultimately, the function of marketing is to communicate value to the market by engaging it through various touch points. The number of possible touch points has grown and changed over time, requiring marketing strategy to appropriately adapt. The use of social media as a new touch point in terms of a marketing tactic has widely been adopted by most businesses. Despite its wide use, marketing theory has not yet developed or caught up to this new phenomenon with respect to Facebook and brand perception. Context regarding this dilemma and its relative importance to marketing theory is addressed in the background of the study.

\section{Purpose of the Study}

The purpose of this qualitative single case study is to understand better what influence the use of Facebook has on users' perception of the brand in Small to Medium Size Enterprises (SMEs). The case is defined as the SME to be known in this study by the pseudonym, The Place, as a restaurant and hotel complex along the Mississippi river in a small Midwestern town. The Place has been in the hospitality business since 1890 and has grown considerably over the last thirty years to include regional and national music acts throughout the summer months on their outdoor stage. The Place offers mostly organic and locally grown gourmet food, regional wine parings, and a wide range of craft beer selections. In their nationally designated historic building, the restaurant shares space with nine European style rooms that are available for rent. In addition, eight other rooms in separate buildings within their grounds are also available for rent. Their core target market is weekend tourists and travelers from the larger metro areas that reach out approximately two hours driving time. Though they have a loyal local following, over $60 \%$ of 
their business comes from outside their geographic customer base. The establishment is known both for its unique food offerings and location along the bluffs of the Mississippi river. The Place recently has undergone an ownership change, replacing 31 years of continuous control. The new owners are committed to leveraging their existing web and email presence with vigorous use of Facebook as a marketing communication tool.

In light of changing economic pressures, organizations typically struggle with the allocation of their marketing dollars and the related return on investment. Due to this scarcity, having knowledge of what Facebook can and can't do when considering brand perception might allow SMEs to improve their market engagement. As the analysis of Facebook being a marketing communication tool is in the developmental stage, the timeliness of this study is very relevant, especially as Facebook engages in monetizing their business model.

\section{Research Question:}

The main research question for this study is RQ1: How do companies Facebook communication strategies influence the user's perception of the brand in Small to Medium Size Enterprises (SMEs)?

As a qualitative case study, a social constructivist approach was taken by the researcher that acknowledges a worldview contingent upon reality having multiple meanings based on experiential interaction between both individuals and their environments. The theoretical/conceptual framework was built on marketing theories developed by Morgan and Hunt [18] and that of Novak, Hoffman, and Yung [19]. In furthering the relationship marketing theory posited by Dwyer, Schurr, and Oh [20], Morgan and Hunt [18] developed the Key Mediating Variable (KMV) model of relationship marketing based on the two constructs of relationship commitment and trust. Morgan and Hunt [19] argued that the two constructs were mediated by the five antecedents of relationship termination costs, relationship benefits, shared values, communication, and opportunistic behavior. In turn, relationship commitment and trust bore out an increase of acquiescence and cooperation, but a lack of it increased propensity to leave, functional conflict, and uncertainty. The basis of the KMV model of relationship marketing is the outcome of successful relationship marketing efforts must be based on cooperative behaviors of both the organization and user.

The researcher leveraged the KMV model by further developing the notion that relationship commitment and trust indeed influence cooperative behaviors and therefore general positive brand perceptions. The effect that Facebook has on the relationship was researched to appreciate more the developing phenomenon of relationship marketing via social media sites based on Morgan and Hunt's [18] commitment and trust construct.

In addition, the researcher's theoretical/conceptual framework also takes into consideration the structural modeling approach in online environments developed by Novak et al. [19]. Specific to the online environment, Novak et al. [19] argues that due to the unique virtual interactions, the consumer was lost in the moment or flow as denoted by F as the content, affecting both thoughts and perceptions. Under this approach, it is believed that interactions in the online environment could be very powerful when the communications were experiential, rather than task oriented. Based on the construct of flow, the commitment by the user in this format requires focused attention in the navigation process, which results in the screening out of various thoughts and perceptions.

The study was guided by both the KMV model [18] and the structural modeling approach to the customer experience [19]. By linking both marketing theories, one established on relationship marketing [18] and the other developing theory in the online environment, it is hoped to further marketing theory by looking into the gap that exists relative to the use of social media by organizations and that of brand perception.

To date, little has been studied on how relationship marketing concepts can be operationalized within the context of virtual communications to enhance brand perceptions based on user and brand interactions. This gap is especially true when being investigated through the social constructivist lens, as the study attempts to do. Figure 1 is the conceptual model created by the researcher to connect the established KMV and structural modeling approach to customer experience.

The research seeks to better understand to what extent a SMEs Facebook page and resulting co-created content has on the perception of the brand by the user. In addition, the study hopes to explain how the constructs of trust and understanding are developed within the framework of a Facebook page by content being encoded and decoded by the user and brand.

\section{Methodology}

A qualitative non-experimental single case was conducted to properly address the proposed research questions 


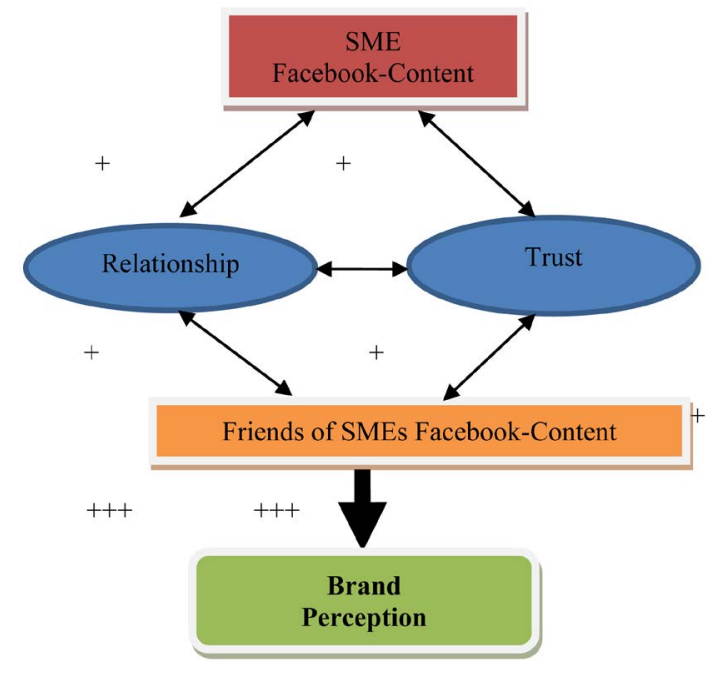

Figure 1. Conceptual model.

and purpose. This type of case approach is appropriate to use when the phenomenon being studied is representative or common-place as is the use of Facebook by SMEs [21]. According to Creswell [22], qualitative data is that which is collected on-site where participants are experiencing the issue that is being studied and analysis is conducted to interpret the data. Since perception can often be subjective, a qualitative study was used to determine the varying perceptions of the sample. The research design follows an interpretivist philosophic tradition in that participants will relay their stories and the researcher will interpret these stories to find the impact the social media has, if any, on the perception of the brand.

Recent evidence of using the case study approach in investigating the use of social media by SMEs has shown promise. Using a case study to better understand how individuals make choices based on information provided by users of a travel review blog, Hardey [13] determined this methodology generated important feedback that would not have been realized using other research designs. Building on eWOM (electronic word-of-mouth) theory, Hardey [13] was able to add substantive insight into how one organization and its users interacted in this changing mode of communication. Not meant to build a model of how to use this social media portal, but rather to gain a greater appreciation for how it is used, Hardey [13] found the case study method yielded rich context to the larger issues regarding the use of social media.

The advantage of using a case study regarding the use of social media by SMEs can be linked to work conducted by O'Donnell, Gilmore, Carson, and Cummins [23]. Though not specifically looking at the use of social media, the O'Donnell et al. [23] study did seek to better understand the role networking has on SME susing the case study approach. It has generally been accepted that the use of social media is very similar to traditional face-to-face networking strategies to build relationships within the marketing field [17].

\subsection{Setting/Instrumentation/Measures}

The participating SME for this single case study and virtual setting was The Place's Facebook page. Potential participants were recruited to be in the study via a Facebook post by the owners asking for volunteers. The volunteers than liked the researchers Facebook page indicating they would like to be in the study and the researcher than contacted the individual using Facebook chat to fill out the informed consent form and find a convenient time to conduct the interview. Demographics of the participants can be found in Table A1 of the Appendix. All interviews were conducted virtually via the chat function within Facebook between the researcher and participant's Facebook page. These chat secessions only could be seen or viewed by the researcher and the participant. The chat secessions lasted approximately 40 minutes and typically were conducted on an agreed upon date and time by the researcher through mostly email communication with the participant. However, some were scheduled using Facebook chats as well. At the end of the chat secession, the researcher saved the interview in a separate word file and then deleted the chat secession in Facebook and also "defriended" the participant. The researcher's Facebook page for these interviews has also been deactivated since the study is complete. In addi- 
tion, the researcher used the setting to observe over several weeks the interactions between The Place and its Facebook friends.

Following the interview question hierarchy developed by Cooper and Schindler [24], the interview questions were constructed by the researcher after careful consideration of the research purpose, review of literature, and content understanding. It also should be noted that data collected both from internal document review and observation within the setting lead to the formulation of the questions.

To improve validity, the interview questions were field tested by both scholarly experts and organizations at the practitioner level as suggested by Creswell [22]. After several iterations, the researcher also conducted mock or practice interviews with several colleagues to further limit threats to validity. Semi-structured interview questions were chosen to allow for flexibility, as qualitative research often builds upon itself during the data collection process [22].

\subsection{Data Analysis}

In order to prepare the data for efficient and effective analysis, proper cataloging was necessary using several techniques. Data from both the internal document review and the observations were summarized, categorized, and inputted into a database created by the researcher using Microsoft excel. The interview data was coded and entered into the qualitative research software tool nVivo available at the researcher's university.

Analysis of all three data sets sought to better understand and develop thematic takeaways that related specifically to the research question and purpose statement of the study. Miles and Huberman [25] suggest using a similar analysis protocol regardless of the type of data being analyzed. Within this context, Yin [21] also believes an analysis plan that is consistent and based on the research question and literature review is necessary for the integrity of the study and chosen methodology.

For each source of data, a contact summary sheet was used that included an analysis of the problem, brief description, illustration, variations, advice, and time required [25]. This brief overview sheet was used for all data sources and as a means to better categorize the data. In addition, the specific data analysis technique used was explanation building. Explanation building is a case study technique that is used when the study seeks to explain a phenomenon in an iterative process that will further develop ideas [21].

\section{Findings}

As necessary in a case study, triangulation of three data sets was conducted. Data from the review of The Place's internal documents and Facebook page observations were used for both analysis and also development of interview questions that yielded the third set of data from participant answers. The triangulation of these three data sets was then used to answer the research questions by the formation of connected themes.

As the interview questions and correlating responses from the participants [along with data from the internal document and observations] are related to the categorical themes drawn from the research sub-questions, the analysis therefore is also proportional to those five categories of connectivity, change of perception, internal value, goodwill, and decision process. Participants felt an increase in their relationship with the brand based on their interactions through Facebook. This increased their connectivity, which in turn drove a greater sense of loyalty to the brand that was different prior to being friends of the SME's Facebook page. Conversations with the owners, observations from their Facebook page, and review of internal documents also confirm this result.

The participants also reported their communications with the SME's Facebook page maintained or increased their overall positive perception of the brand. Dramatic increases in the SMEs Facebook friends and sustained participation based on the analytical review of the site also suggest a general appreciation for the brand. The unique features of Facebook's ability to allow for the immediate co-creation of content and the ease of adding visuals were found to be a driving force for this perceptional increase. The participants also noted a benefit to the value that interacting with the organizations Facebook has on personality traits such as self-esteem and pride. Responses generally tended to be positive in nature when asked whether the goodwill of the brand increased due to Facebook interactions. Much like the perception of the brand and internal value, the participants reported this to be Facebook specific relative to other marketing communication tools such as a webpage or email newsletter.

Finally, the decision making process category provided insights into whether Facebook promotes the process of organizational patronage. With few exceptions, Facebook use did have some influence on the participants' eventual use of the SME's product/service. The evidence suggests that the other categorical themes played a part 
in the intent to purchase and a strong link exists that all have Facebook use in common.

From the detailed responses on the SME's use of Facebook and the respondents' perception of the brand when taking into account their interactions within the realm of Facebook, use of Facebook appears to be an effective means of maintaining and often enhancing the perception of the brand in the positive. While not all participants identified Facebook as the main driver of perceptual change, all indicated a preference for Facebook as their major source of information and communication with respect to the brand. In the analysis of the data, thematic units were identified that were grouped into the categories of connectivity, change perception, internal value, goodwill, and decision making process. A detailed link between the category label and interview questions can be found in Appendix B.

\subsection{Connectivity}

The questions at the core of determining connectivity dealt with "why do the consumers or potential consumers interact with the brand's Facebook"? For the purpose of this study connectivity is defined as the link between the brand and user. In addition, connectivity also refers to the means and ease by which the link occurs. A series of probing questions ultimately sought to determine why the participants friended the SME's Facebook page. Decidedly, the respondents felt Facebook was the best option to stay connected to the brand and also the most efficient. Kelly's comment of "wanting to always know what the specials are and what is going on that weekend" was a common description of why she and others actively sought out the organizations Facebook and page and friended them. In addition, comments like Todd's "Facebook is easier and more convenient then trying to find stuff on their website" also were standard answers for why they are Facebook friends with the SME. Common or similar responses of "it is easier than the website", "always connected" "natural” and "always updated” provide context to the majority of the participants who feel a greater degree of connectivity through Facebook as opposed to either email or The Place's website. However it should be noted that three respondents did indicate indifference and one a preference for The Place's website with the comment "habit for me still is to go to their website first."

\subsection{Change of Perception}

Several interview questions were used to determine if the participants' perceptions of the brand was affected by their interactions with the brand its Facebook page. The interview questions centered around a) their perception of the brand in general; b) what effect their Facebook interaction had on their brand perception; and c) what is unique if anything about Facebook relative to their perception of the brand in comparison to other means of communication like their website or email. As with the connectivity category, the participants felt a strong preference for the brand's Facebook over their website or email newsletter when taking into account maintaining or enhancing their perception of the brand. For example, Dawn commented that "I have always loved this place and the ability to tell others on Facebook made me feel good...” This type of word-of-mouth advertising seemed to have a positive effect on others' views of the SME and actually strengthened it. Tim noted that "when I read other positive comments on their wall it validates my decision to return.” Specifically, Facebook seems to drive more positive passion for the brand, which can be argued as a positive perceptual change. As the research did not measure empirically brand perception, pre- and post-Facebook, the subjectivity is drawn from the participants' observations.

\subsection{Internal Value}

When asked what internal value (pride, self-esteem, etc.) they obtained from interacting with the brand's Facebook page, interview participant responses were similar in nature (positive) to that of the perception of the brand. Bobby's comment "I feel important when I make a post or comment on someone else's post because I know they are reading everything” was an often repeated theme by the participants. As with the connectivity and perception of the brand category, respondents felt a unique distinction in offering increased internal value by their Facebook communications with the brand in comparison to either the SME's webpage or email newsletter. In describing the difference, all of the study participants eagerly reported that their own ability to build the brand with their own pictures, comments, likes, and shares was a differentiating feature specific to Facebook. As an example, Bobby reports that "I feel important when I make a post or comment on someone else's post because I 
know they are reading everything". Kimmy agreed in her comment of "that fact that when I make a comment and they respond to it makes me feel good". It should be noted though that a large spectrum of participation in those activities was recorded, and the strength or weakness within each was not studied.

\subsection{Goodwill}

Related to perception of brand, but distinctly different, the series of interview questions that tried to capture the participants' assessment of whether their use of Facebook had an impact on brand goodwill uncovered an interesting finding. With few exceptions, it appeared evident that the brand's Facebook interactions with the respondents promoted goodwill and was so strong in many cases that the positive goodwill was passed along. As Eleanor noted regarding the power of Facebook when commenting on goodwill "I wanted to share my feelings about [the business] with others and let the owners know what a good job they are doing... isn't that the purpose of Facebook?” This example was repeated by others with respect to the building and passing along of the brand's goodwill.

\subsection{Decision Process}

A final category based on interview questions related to the decision making process individuals use to patronize the brand or not when taking into account their use of Facebook. The respondents reported a general appreciation for the role that Facebook plays. With a few exceptions, participants of the study agree that their friending of the SME's Facebook page at times provided the momentum to make a purchase. Shaun captures the majority of the comments when he states "Was not planning on going there the other day and then got a newsfeed update from them saying they were running a special... we went". He then added that "I would not have every gone to their website, the information came to me.” Dawn reiterated Shaun's view with her belief that "they send the perfect amount of information to me to make informed decisions as there is not a lot of thinking that really needs to go into it... very spur of the moment.” Those that did not connect Facebook to a purchase, commented that it was "hard to differentiate" between their knowledge of the brand and eventual purchases. For the others however, the "spontaneity" of the brand's Facebook updates and newsfeeds increased the motivation to think about the brand as an option for something to do. Since visiting their website was not a daily or even weekly action, an almost daily reminder of the brand appears to be a primary factor in the brand becoming part of their evoked set relative to their product/service.

\subsection{Summary}

Interactions between the SME and individuals through Facebook appears to have a positive effect on the perception of the brand due to its unique connectivity features, which in turn influences the goodwill offered by the users. The combination of these factors also appears to have the net effect of Facebook being a catalyst in ultimate purchase decisions. Additionally, by providing a sense of community and having the ability to co-create the content, the users of the brand's Facebook page recognize the uniqueness of Facebook as a marketing communication tool. It should be noted though that not all respondents (10\% - 25\%) could attribute Facebook as a major force in shaping their perception of the brand. It appears it was difficult for these individuals to separate Facebook from the other integrated methods they had previously been exposed to. A point to consider also is the influence the sample might have had on the study. The results most likely reflect the participants all being Facebook friends of The Place and current or past customers.

\section{Conclusions}

Brand perception is a complex and multi-leveled construct. Researchers have identified that positive brand perception has a result of managing marketing functions to develop a relationship in an integrated manner that leverages current and emerging marketing communication tactics. Both Morgan and Hunt [18] and recently Novak et al. [19] have contributed to this construct on relationship between marketing and the theory in the online environment respectively. Standing alone, scholarship of brand perception is developing and complicated by the emerging marketing tools, then technology is creating [23]. In addition, the addition of social media portals like Facebook to Integrated Marketing Communication (IMC) strategy to build and maintain a brand is not fully understood [5]. The data collected from the participants of this single-case qualitative study offer some insight into 
the developing scholarship surrounding Facebook, brand perception, and IMC strategy.

Several insights drawn from the research findings support the use of Facebook by SMEs to maintain and/or enhance the perception of the brand in the positive. Analysis of the data shows that the use of Facebook by the SME and engagement by the user leads to a) greater connectivity with the brand; b) a substantial factor in the influence of the perception of the brand; c) a factor in driving the internal value assigned by the user; d) promotion of goodwill between the brand and user; and e) a tendency to promote ultimate purchase within the consumer decision making process. These outcomes appear to be driven by the SME's use of Facebook, which allows the user uniquely to co-create content through comments, likes, and shares. In addition, the ability to access the changing information spontaneously with accompanying visual stimuli strengthens the relationship between the user and brand. Within this framework, a strengthening of the perception of the brand from Facebook participation has an influencing effect. Several recommendations for both the scholarship and practitioner use that are supported by this research are:

\section{Theoretical Implications}

With the seminal work of Kotler [26], a basis for marketing and the management of its function has been accepted as a set of tasks needed to be formalized to communicate the value proposition to the intended market. Building on Kotler's [27] work, both Hunt [28] and Porter [29] furthered marketing theory by arguing for the development of relationships between the brand and customers that can result in a distinctive competitive advantage. Post-Facebook, little research exists that incorporates Facebook use by SMEs as part of general marketing theory. Based on the responses from the participants of this study, some conclusions can be drawn. A strong sense of community and therefore relationship was reported. Serving a main function of marketing to create and communicate value, Facebook can build the necessary touch points needed and required to build brand value. The uncovering of this insight seems similar to Kohli and Jaworski's [30] finding that an organization needs to communicate value in order to develop a long-lasting competitive advantage. Based on the responses from the study's participants, if used correctly by the brand, Facebook has the ability to be the differentiating value proposition.

The importance of IMC strategy first argued by Hunt [28] in building a brand that results in positive perception has gained wide acceptance as a common marketing theory [31]. While the exact formula to integrate all of the possible marketing communication tactics is firm and market specific, it is clear that a multi-faceted approach that uses a single voice is necessary to develop a brand. Mangold and Faulds [15] have found in a comprehensive study that there is much anecdotal evidence to suggest some return on investment relative to social media, yet scant empirical evidence exists or is supported by scholarly research. To wit, the analysis of data from this study offers potential. At the core, respondents felt the SME's Facebook page and interactions with its friends added to and in most cases were more valuable to the other forms of marketing communication tools used by the brand. As part of their IMC strategy, it was felt by the study respondents that Facebook outperforms other communication forms and therefore directly maintained and/or enhanced brand perception. This result helps confirm the work done by both Kliatchko [32] and Castronovo and Hung [5] that social media sites like Facebook offer a unique channel to potential and current customers of a business.

The Study also provides valuable information for practitioners, especially those that have limited marketing expertise and/or budgets as is the case in many SME's. The results of this study indicate that organizations can indeed maintain or build their positive brand image by focusing on the co-creation of the content that leverages the use of pictures and personal stories by the users. Simply updating the page daily by the SME appears to have little effect on the perception of the brand by the user. However, shares, likes, and comments by the users has a validating effect not seen by other forms of marketing communications. Practitioners would be wise to design and operate their Facebook page that stimulates the visual and provides opportunity for the co-creation. The research also indicates that treating a Facebook page as merely an informational medium like a website is misguided. This study suggests that the power in a Facebook page when trying to build brand perception comes from the expressions shared by numerous sources. Practitioners need to be conscious of this as they integrate their Facebook page with the other marketing communication tactics available for branding purposes.

\section{Limitations}

Important factors relative to this study have the potential to impact the research findings. All respondents were 
familiar with the brand, would be considered mostly repeat customers, and generally had a positive opinion of the brand. Also, a significant number of respondents were eager to participant in the study and were early adopters to Facebook. At the time of the study, Facebook was very popular, in the media and had little competition. This dynamic certainly could change and would not be unusual in the rapidly changing social media environment. In addition, the single case study approach might yield responses that resulted in the specific use of Facebook by the chosen SME. How they use Facebook and interact with their friends is certainly not universal in nature. Another limitation of this study is investigating those that use Facebook, but have a preference for website or email communication. As noted in Chapter 1, other limitations include: a) participants under the age of 18 were not allowed in the study and their input could provide meaningful information; b) individuals familiar with the SME's brand, but not Facebook "friends" of the SME were excluded from the study; c) the interview medium used might hinder participant in depth answers; and d) analysis of data has potential researcher bias due to the methodological approach.

\section{Recommendations for Further Research}

Conducting this research study at other organizations of different sizes, geographic locations, and industries would provide deeper understanding and possible distinction between how the cooperating host used Facebook in relation to others. In addition, an effort to specifically separate Facebook from the other forms of marketing communication specific to brand perception would better determine the level of importance placed by the individual. Also, investigating the specific attributes of Facebook posts, comments, pictures, etc. as a contributing factor to brand perception rather than the holistic approach used in this study would lend more texture to the conversation. Another area of interest would be investigating the brand perception of those not currently knowledgeable about a brand or the brands Facebook friend. What effect Facebook has on the user after becoming the SME's friend should be investigated since this sample was excluded from the study. Furthermore, the insights and themes drawn from this study could be used to find more generalizable meaning using a different research design. In doing so, a model for developing brand perception within the Facebook framework could be developed for additional research or use by practitioners. A last recommendation for further study not supported by this data, yet within the parameters of the research question, is investigating brand perception using other social media portals like Twitter.

\section{References}

[1] Hardey, M. (2011) Generation C: Content, Creation, Connections and Choice. International Journal of Market Research, 53, 749-770. http://dx.doi.org/10.2501/IJMR-53-6-749-770

[2] Mangold, W.G. and Faulds, D.J. (2009) Social Media: The New Hybrid Element of the Promotion Mix. Business Horizons, 52, 357-365. http://dx.doi.org/10.1016/j.bushor.2009.03.002

[3] Piskorski, M. (2011) Social Strategies That Work. Harvard Business Review, 89, 116-122.

[4] Sago, B. (2010) The Influence of Social Media Message Sources on Millennial Generation Consumers. International Journal of Integrated Marketing Communications, 2, 7-18.

[5] Castronovo, C. and Huang, L. (2012) Social Media in an Alternative Marketing Communication Model. Journal of Marketing Development \& Competitiveness, 6, 117-136.

[6] Sago, B. (2010) The Influence of Social Media Message Sources on Millennial Generation Consumers. International Journal of Integrated Marketing Communications, 2, 7-18.

[7] Boyd, D.M. and Ellison, N.B. (2008) Social-Networking Sites: Definition, History, and Scholarship. Journal of Computer-Mediated Communications, 13, 210-230. http://dx.doi.org/10.1111/j.1083-6101.2007.00393.x

[8] McLaughlin, C. and Davenport, L. (2010) Brand Community Success Factors: A Study of Two Facebook Brand Community Features. American Academy of Advertising Conference Proceedings, 1, 78-79.

[9] Internet Stats. (2012) http://www.adweek.com/information

[10] Owen, R. and Humphrey, P. (2009) The Structure of Online Marketing Communication Channels. Journal of Management \& Marketing Research, 4, 54-62.

[11] Facebook Statistics. (2012) http://www.facebook.com/statistics

[12] Lipsman, A., Mud, G., Rich, M. and Bruich, S. (2012) The Power of “Like”: How Brands Reach (and Influence) Fans through Social-Media Marketing. Journal of Advertising Research, 52, 40-52.

http://dx.doi.org/10.2501/JAR-52-1-040-052 
[13] Hardey, M. (2011) Generation C. International Journal of Market Research, 53, 749-770. http://dx.doi.org/10.2501/IJMR-53-6-749-770

[14] Piskorski, M. (2011) Social Strategies That Work. Harvard Business Review, 89, 116-122.

[15] Mangold, W.G. and Faulds, D.J. (2009) Social Media: The New Hybrid Element of the Promotion Mix. Business Horizons, 52, 357-365. http://dx.doi.org/10.1016/j.bushor.2009.03.002

[16] Ankeny, J. (2012) Facelift. Entrepreneur, 39, 56-59.

[17] Spiller, L., Tuten, T. and Carpenter, M. (2011) Social Media and Its Role in Direct and Interactive IMC: Implications for Practitioners and Educators. International Journal of Integrated Marketing Communications, 3, 74-85.

[18] Morgan, R.M. and Hunt, S.D. (1994) The Commitment-Trust Theory of Relationship Marketing. Journal of Marketing, 58, 20-38. http://dx.doi.org/10.2307/1252308

[19] Novak, T.P., Hoffman, D.L. and Yung, Y.F. (2000) Measuring the Customer Experience in Online Environments: A Structural Modeling Approach. Marketing Science, 19, 22-42. http://dx.doi.org/10.1287/mksc.19.1.22.15184

[20] Dwyer, F., Schurr, P.H. and Oh, S. (1987) Developing Buyer-Seller Relationships. Journal of Marketing, 51, 11-27. http://dx.doi.org/10.2307/1251126

[21] Yin, R.K. (2009) Case Study Research, Design and Methods. 4th Edition, Sage, Thousand Oaks.

[22] Creswell, J.W. (2009) Research Design: Qualitative, Quantitative, and Mixed Methods Approaches. 3rd Edition, Sage Publications, Thousand Oaks.

[23] O’Donnell, A., Gilmore, A., Carson, D. and Cummins, D. (2002) Competitive Advantage in Small to Medium-Sized Enterprises. Journal of Strategic Marketing, 10, 205-223. http://dx.doi.org/10.1080/09652540210151388

[24] Cooper, D. and Schindler, P. (2011) Business Research Methods. 11th Edition, McGraw Hill, Boston.

[25] Miles, M.B. and Huberman, A.M. (1994) Qualitative Data Analysis: An Expanded Sourcebook. Sage Publications, Beverly Hills.

[26] Kotler, P. (1973) The Major Tasks of Marketing Management. Journal of Marketing, 37, 42-49. http://dx.doi.org/10.2307/1250357

[27] Kotler, P. (2005) The Role Played by the Broadening of Marketing Movement in the History of Marketing Thought. Journal of Public Policy \& Marketing, 24, 114-116. http://dx.doi.org/10.1509/jppm.24.1.114.63903

[28] Hunt, S.D. (1976) The Nature and Scope of Marketing. Journal of Marketing, 40, 17-28. http://dx.doi.org/10.2307/1249990

[29] Porter, M.E. (1979) How Competitive Forces Shape Strategy. Harvard Business Review, 57, 137-145.

[30] Kohli, A.K. and Jaworski, B.J. (1990) Market Orientation: The Construct, Research Propositions, and Managerial Implications. Journal of Marketing, 54, 1-18. http://dx.doi.org/10.2307/1251866

[31] Smith, B.G. (2010) Beyond Promotion: Conceptualizing Public Relations in Integrated Marketing Communications. International Journal of Integrated Marketing Communications, 2, 47-57.

[32] Kliatchko, J. (2005) Towards a New Definition of Integrated Marketing Communications (IMC). International Journal of Advertising, 24, 7-34. 


\section{Appendix A}

\begin{tabular}{|c|c|c|c|}
\hline Participant Pseudonym & Gender & Time Having Facebook Account & Time being friends with The Place \\
\hline "Kelly” & Female & 4 years & 6 months \\
\hline “John” & Male & 5 years & 3 months \\
\hline "Elizabeth" & Female & 2 years & 2 years \\
\hline "Mike" & Male & 4 years & 1.5 years \\
\hline “Maria” & Female & 3 years & 3 years \\
\hline "Ryan” & Male & 5 years & 3 years \\
\hline "Samantha" & Female & 4.5 years & 1 year \\
\hline “Shaun” & Female & 4 years & 6 months \\
\hline “Kimmy” & Female & 5 years & 3 years \\
\hline "Todd" & Male & 5 years & 6 months \\
\hline "Katie" & Female & 5 years & 1 month \\
\hline "Ruth" & Female & 2 years & 9 months \\
\hline “Justin” & Male & 4 years & 1.5 years \\
\hline “Dawn” & Female & 5 years & 2 years \\
\hline "Dustin” & Male & 6 years & 2 years \\
\hline "Eleanor" & Female & 4 years & 3 years \\
\hline “Glenn” & Male & 1 year & 2 months \\
\hline “Amy” & Female & 6 years & 1.5 years \\
\hline “Tammy” & Female & 3 years & 1 year \\
\hline "Bobby" & Female & 4 years & 2 years \\
\hline “Tim” & Male & 5 years & 6 months \\
\hline
\end{tabular}

\section{Appendix B: Link between Category Label and Interview Questions}

1. Connectivity (RQ2-Why do consumers or potential consumers interact with the brand's social media outlets?) Connectivity is defined as that between the SME and its Facebook friends.

2. Change of Perception (RQ3-How does the use of social media by the consumer change their brand perception?) Change of perception is defined as the effect using Facebook by the users had on their perception of the SME and if so, in what way.

3. Internal Value (RQ4-What internal value (pride, esteem, etc.) does the consumer obtain from using the social media of a brand?). Internal value is defined as what feelings are associated with the user interacting with the brand's Facebook.

4. Goodwill (RQ5-How does the use of social media by consumers for a brand relate to feelings of goodwill towards the brand?) Goodwill is defined as the status of the brand assigned by the Facebook user as a result of interactions.

5. Decision Process (RQ6-What affect does the way in which the brand interacts with the consumer using social media have on the consumer's decision to purchase?). Decision process is defined as the steps taken to consumption and what effect Facebook use had on it. 
Scientific Research Publishing (SCIRP) is one of the largest Open Access journal publishers. It is currently publishing more than 200 open access, online, peer-reviewed journals covering a wide range of academic disciplines. SCIRP serves the worldwide academic communities and contributes to the progress and application of science with its publication.

Other selected journals from SCIRP are listed as below. Submit your manuscript to us via either submit@scirp.org or Online Submission Portal.
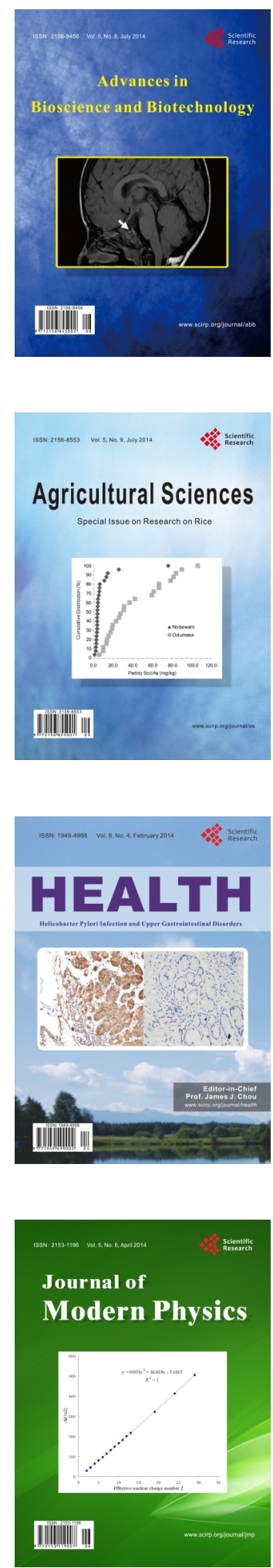
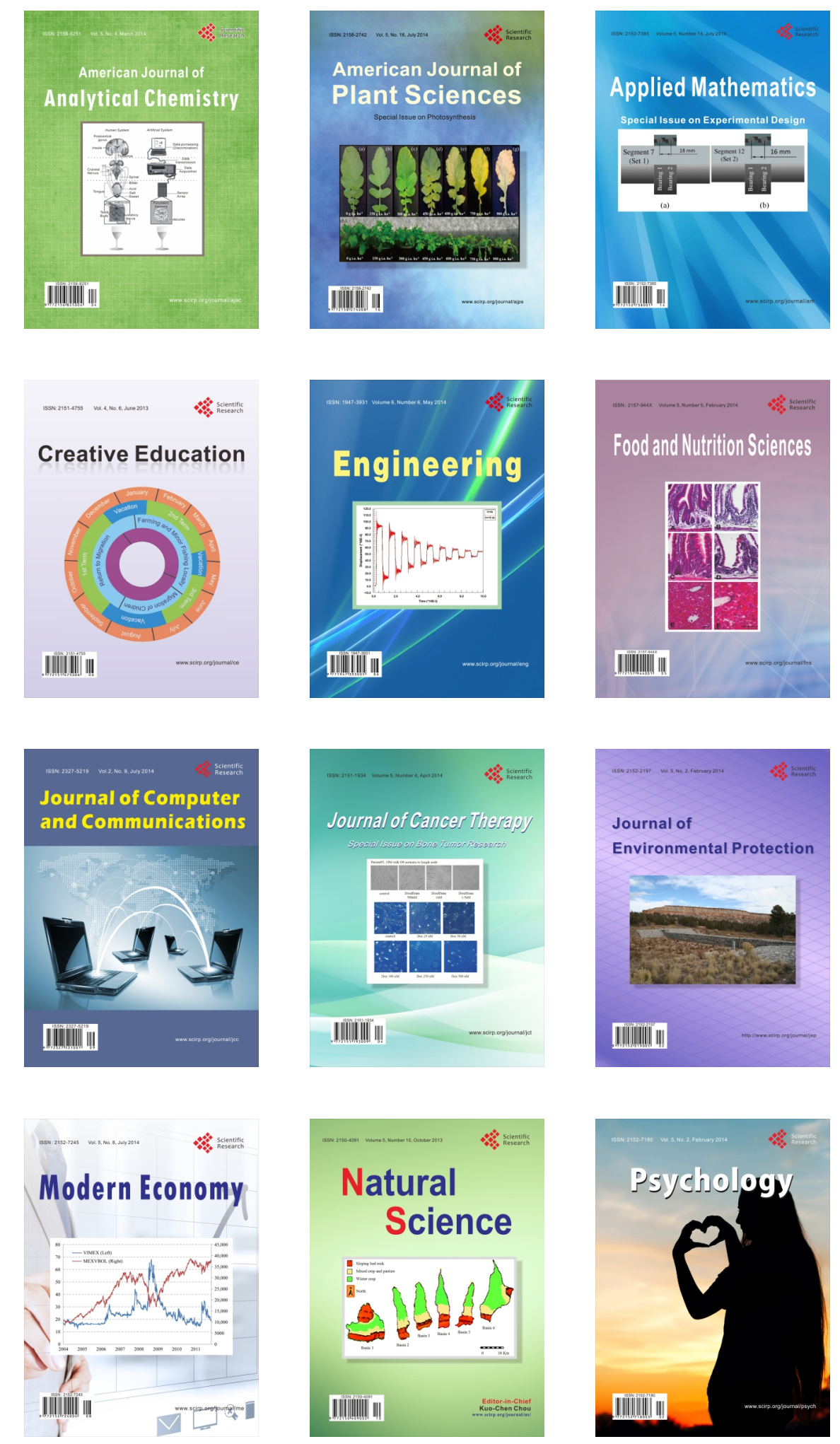